\title{
Latent inhibition of the rabbit's nictitating membrane response as a function of CS intensity*
}

\author{
PAUL R. SOLOMON, GEORGE BRENNAN, and JOHN W. MOORE \\ University of Massachusetts, Amherst, Massachusetts 01002
}

\begin{abstract}
A series (450) of preexposures to a tone CS retarded subsequent conditioning of the rabbit's nictitating membrane response (NMR). Retardation relative to nonpreexposed controls was observed with strong $(95 \mathrm{~dB})$ as well as weak $(75 \mathrm{~dB})$ tones. A subsequent experiment involving summation tests in which the tone was compounded with an excitatory (light) CS as a function of tone intensity suggested that preexposure resulted in a loss of salience rather than active inhibition.
\end{abstract}

Lubow and Moore (1959) coined the term "latent inhibition" in reference to the fact that as few as $15-20$ nonreinforced CS presentations can retard subsequent conditioning (cf. Lubow, 1973). Investigators in this area have recognized two interpretations of latent inhibition. One, which Reiss and Wagner (1972) termed "CS habituation," portrays latent inhibition as an instance of attention decrement (loss of salience) resulting from habituation of the orienting response. An alternative interpretation emphasizes the possibility that latent inhibitors possess CR-antagonistic properties like those of conditioned inhibitors (cf. Lubow, 1973; Rescorla, 1969).

\section{EXPERIMENT I}

The purpose of Experiment I was to determine whether a latent inhibition effect (i.e., retardation of conditioning) could be obtained with the rabbit NMR using a strong auditory CS $(95 \mathrm{~dB})$ as well as one of weaker intensity $(75 \mathrm{~dB})$. Lubow, Markman, and Allen (1968) investigated the effects of CS preexposure on subsequent conditioning of the rabbit's pinna response. Experiment II of their study investigated the effects of CS intensity with four groups of animals receiving 40 preexposures of a tone at intensities ranging from 68 to $77 \mathrm{~dB}$. Relative to nonpreexposed controls, retardation of acquisition was not a function of CS intensity. Although the range of intensities employed by Lubow et al was rather narrow, their results may be inconsistent with the habituation hypothesis because of the failure to observe greater retardation with soft tones compared with louder tones (cf. Thompson \& Spencer, 1966, p. 19).

\section{Method}

Subjects. The Ss were 48 experimentally naive New Zealand albino rabbits maintained on food and water ad lib throughout the experiment.

*This research was supported by National Science Foundation Grant GB-24557. Requests for reprints should be sent to John W. Moore, Middlesex House, Department of Psychology, University of Massachusetts, Amherst, Massachusetts 01002.
Apparatus. The apparatus and methods used to condition the rabbit's nictitating membrane response are basically those described by Gormezano (1966) and Marchant, Mis, and Moore (1972). The UCS was a $2-\mathrm{mA}$ ac shock of $50 \mathrm{msec}$, administered through two stainless steel wound clips implanted in the skin, one placed just below the right eye and one placed lateral and in back of the right eye. The CSs were $1200-\mathrm{Hz}$ tones of $75 \mathrm{~dB}$ or $95 \mathrm{~dB}$ SPL, depending upon the experimental group.

Procedure. Ss were randomly assigned to four groups, with 12 Ss per group. Each $S$ participated in the experiment for a period of 50 min on each of 8 days. On Day 1 , each $\mathrm{S}$ was habituated to restraint and experimental chamber. On Days 2, 3,4, 5, and for one-half of the experimental session of Day 6 , control Ss simply remained in the chambers with no stimulus presented, whereas preexposed Ss received 100 presentations of the CS (50 on Day 6). On Day 6, after 25 min (or 50 CS presentations for CS preexposed Ss) all animals were given 50 acquisition trials with an interstimulus interval (ISI) of $.5 \mathrm{sec}$ and an intertrial interval (ITI) of $30 \mathrm{sec}$. This was continued for 100 trials on each of Days 7 and 8. The complete experiment comprised a 2 by 2 design with two levels of CS intensity (75 and $95 \mathrm{~dB}$ ) crossed with two levels of CS preexposure (0 and 450). The CS intensity remained constant for each group throughout.

\section{Results and Discussion}

The principle results are presented in Fig. 1, which gives the mean number of CRs for each of the four main groups pooled over the 250 acquisition trials. Analysis of variance indicated significant $(\mathrm{p}<.01)$ main effects of CS-intensity $[F(1,44)=36.60]$, and number of preexposures $[F(1,44)=10.10]$. The interaction of the two principal factors was not significant, nor were other factors of the design such as Days and Replications.

The important point is that a latent inhibition effect emerged for the 95-dB tone as well as the 75-dB tone. However, preexposure of the 95- $\mathrm{dB}$ tone retarded conditioning only $29 \%$ below the level of responding of the 95-dB (nonpreexposed) control group. Retardation relative to controls was $53 \%$ with the weaker tone. Viewed in this way, one could argue that the latent inhibition effect was inversely related to CS intensity. Such an interpretation would be consistent with the notion that retardation of condition following CS preexposures results from a loss of cue salience by way of an habituation-like process.

The fact that retardation was evident despite the 23-h 
EXPERIMENT I-RETARDATION

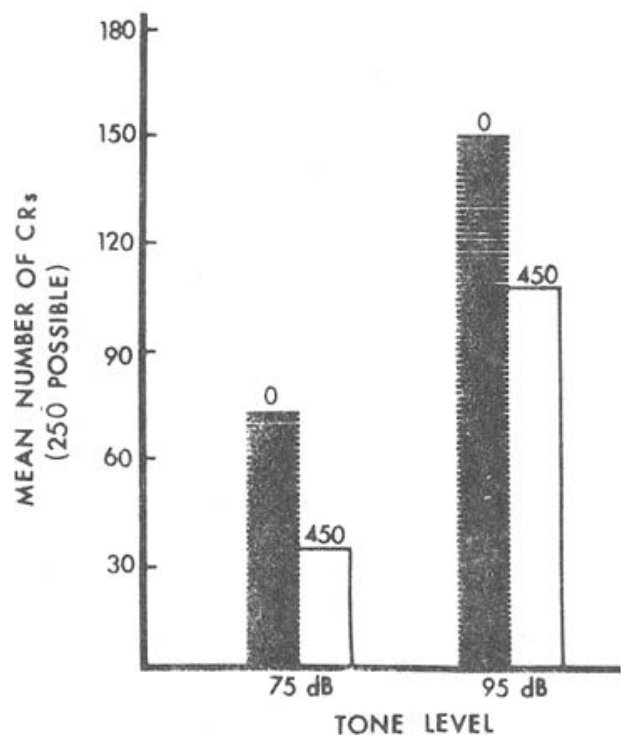

Fig. 1. Mean number of CRs (250 possible) as a function of CS intensity and number of preexposures.

break between the end of preexposure and the start of conditioning is consistent with Siegel's (1970) finding that latent inhibition is retained over a 24 -h interval. The finding that the effects of CS preexposure are retained over a rather long interval seems inconsistent with the notion that habituation to the CS is actually responsible for retardation. Since habituation is subject to spontaneous recovery (Thompson \& Spencer, 1966), it may be that loss of salience results in a "tuning out" at a high level of processing and that this "tuning out" process behaves in a manner somewhat different from habituation of reflexes.

\section{EXPERIMENT II}

Experiment II was designed to assess the inhibitory potential of preexposed tonal CSs of 75 and $95 \mathrm{~dB}$ by means of both summation and retardation tests. Since Experiment I demonstrated that preexposure to tonal CSs of either intensity retards acquisition relative to nonpreexposed controls, a summation test is essential for determining whether this retardation arose from a loss of cue salience, on the one hand, or an active inhibitory process, on the other. A summation test consists of compounding the suspected inhibitor with a previously conditioned excitatory CS. Inhibitory summation is said to occur when (a) conditioned responding to the test compound is less than responding to the excitatory CS alone and (b) this difference exceeds that observed in a group which controls for the fact that the test compound represents a novel stimulus configuration. As Rescorla (1969) has indicated, inhibitory summation plus retardation implies that the stimulus in question is actively inhibitory, i.e., like a conditioned inhibitor. Retardation without summation presumably implies a loss of salience, since an unattended stimulus component neither adds nor detracts from the conditioned strength of another stimulus on an orthogonal dimension. Finally, summation without retardation implies that the compounded stimulus has high salience (producing a summation effect through an attention shift or external inhibition), but no true inhibitory properties.

\section{Method}

Subjects and Apparatus. The Ss were 32 experimentally naive New Zealand rabbits maintained on food and water ad lib throughout the experiment. The apparatus was the same as in Experiment I.

Design and Procedure. On the day following suturing and adaptation to restraint, Ss received 5 days (100 trials/day to a criterion of $90 \%$ CRs) of acquisition to a light CS at an ISI of $.5 \mathrm{sec}$ and utilizing a $2-\mathrm{mA}$ ac infraorbital shock as the UCS. Rabbits were matched on the basis of their conditioning rate to the light with one member of the pair experiencing 450 exposures to the tonal CS presented alone at 75 or $95 \mathrm{~dB}$ SPL while the other merely sat ("sit" controls) in restraint for a comparable period of time (0 exposures). Midway through the fifth day of CS exposure, each member of the pair received 25 light alone and 25 light plus tone trials in an unsystematic order. Summation testing continued the next day with 50 light alone and 50 light plus tone trials following an initial series of 15 reinforced light trials. These were the only UCS presentations during summation testing. All Ss received 100 tone acquisition trials on the day following the summation test and for 2 additional days. Tone intensity was the same as during preexposure and summation testing: $75 \mathrm{~dB}$ for half the animals and $95 \mathrm{~dB}$ for the other half. As in Experiment I, the ITI was a constant $30 \mathrm{sec}$ in each stage of the experiment.

\section{Results and Discussion}

Summation test. Figure 2 presents the mean percentage of CRs to light alone and light plus tone trials for each of the four treatments of the experimental design. Inspection of Fig. 2 reveals that the summation effect was greatest for animals experiencing the 95-dB tone for the first time. ${ }^{1}$ Preexposure to the $95-\mathrm{dB}$ tone reduced the summation effect considerably. Although the addition of the preexposed 75-dB tone to the light produced a slight reduction of conditioned responding, this reduction differed little from that observed in the 75-dB "sit" controls.

Analysis of variance of difference scores (\% CRs to light $-\%$ CRs to light plus tone) indicated significant $(p<.05)$ main effects of number of CS preexposures $[\mathrm{F}(1,28)=13.58], \mathrm{CS}$ intensity $[\mathrm{F}(1,28)=13.58]$, and the interaction of these two factors $[F(1,28)=4.75]$. Planned individual contrasts between difference scores indicated that the difference between the 0 and 450 preexposure conditions was significant at $95 \mathrm{~dB}, \mathrm{t}(28)=$ $4.22, \mathrm{p}<.001$, but not at $75 \mathrm{~dB}, \mathrm{t}(28)=.09$. The pattern of results shown in Fig. 2 provides little support for the hypothesis that preexposure produced an actively inhibitory CS at either tone intensity. 


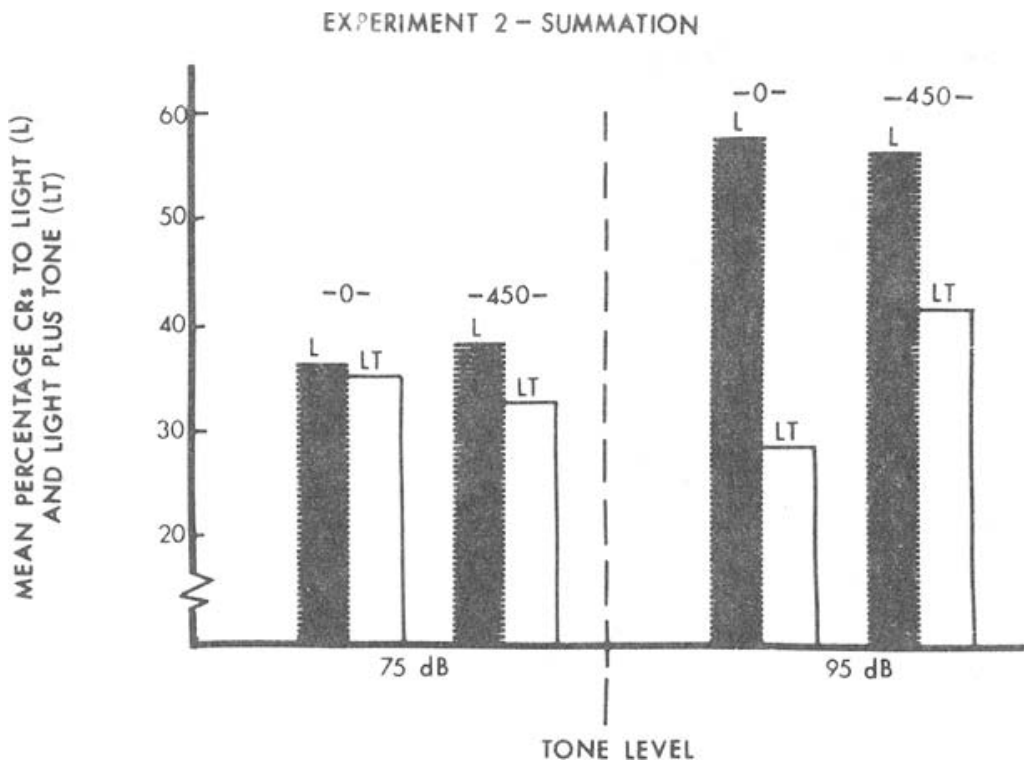

Fig. 2. Mean percentage of CRs to light (L) and light plus tone (LT) as a function of stimulus intensity and number of preexposures.

The observation that preexposure reduced, rather than added to, the summation effect obtained with the 95-dB "sit" controls suggests that summation in the latter case was caused by external inhibition or by a shift of attention from the light. The 450 preexposures evidently reduced this distracting influence of the $95-\mathrm{dB}$ tone.

Retardation Test. Figure 3 presents the mean number of CRs to the tone during the 300 conditioning trials to the tone. Analysis of variance indicated significant $(\mathrm{p}<.05)$ main effects for number of preexposures $[\mathrm{F}(1,28)=8.16]$, CS intensity $[\mathrm{F}(1,28)=41.45]$, and the interaction of these two factors $[F(1,28)=4.40]$. This interaction arose from the fact that the difference between preexposed and "sit" controls was greater at $75 \mathrm{~dB}$ than at $95 \mathrm{~dB}$. The attenuated retardation effect in the 95- $\mathrm{dB}$ case was likely due to a ceiling effect imposed by the overall rapid rate of conditioning to these tones given positive transfer from prior conditioning to the light. Thus, conditioning was more rapid to the $95-\mathrm{dB}$ tone than the $75-\mathrm{dB}$ tone and retarded for both preexposed groups in comparison with their matched "sit" controls. It is interesting from a methodological viewpoint that the latent inhibition effect, i.e., retardation, emerged despite the complexities of initial conditioning to the light and the intervening summation test.

The observation that the 95- $\mathrm{dB}$ "sit" controls gave more CRs in retardation than any of the other group provides additional support for the hypothesis that the large summation effect observed in the preceding stage was due to external inhibition or to a shift of attention away from the light. Finally, the fact that retardation occurred with the preexposed $75-\mathrm{dB}$ tone in the absence of significant difference between preexposed and "sit" controls in summation testing is consistent with a loss-of-salience interpretation of latent inhibition.

\section{GENERAL DISCUSSION}

The findings of the present investigation suggest that latent inhibition of the rabbit's NMR to a tonal CS results from a loss of cue salience. The primary evidence for this conclusion is provided by the results of summation and retardation testing in Experiment II. Preexposure to a tone did not produce a greater summation effect than that observed in matched "sit" controls which had no tone preexposures, and in the case of the 95-dB tone in Experiment II actually reduced the summation effect.

\section{EXPERIMENT 2 - RETARDATION}

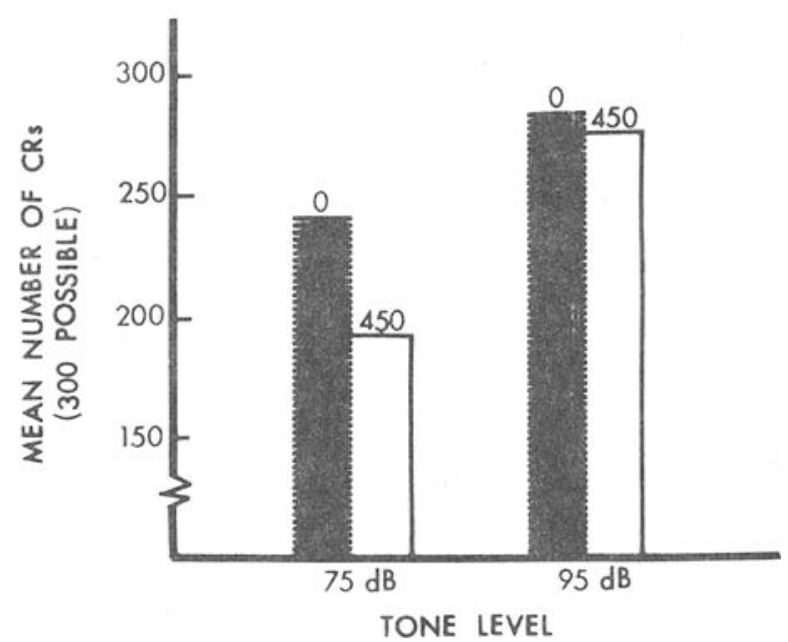

Fig. 3. Mean number of CRs ( 300 possible) as a function of CS intensity and number of preexposures. 
These same observations argue against the hypothesis that preexposure endows the CS with active inhibitory properties.

While generally consistent with the interpretation of latent inhibition of the rabbit eyeblink offered by Siegel (1972) and Reiss and Wagner (1972), there is a good chance that the mechanism responsible for loss of salience through CS preexposure may not conform with the principles of reflex habituation as enunciated by, e.g., Thompson and Spencer (1966). The observations that CS preexposure retarded acquisition to strong as well as weak CSs and spanned an interval of at least one day remain the two potential stumbling blocks for the hypothesis that loss of salience is mediated by habituation. As Lubow (1973) has pointed out in his review of the latent inhibition literature, there is some support from studies investigating the effects of the drug scopolamine (e.g., Carlton, 1969) and hippocampal lesions (e.g., Douglas, 1967) for the notion that preexposure affects central attentional processes. It would be of interest to determine whether the "tuning out" process is also robust with respect to the disinhibiting influence of stimulus change or other alterations of the CS complex. If the central attentional processes are not governed by the laws of habituation, it is possible that such manipulations would fail to reinstate salience to the preexposed stimulus.

\section{REFERENCES}

Carlton, P. L. Brain-aceyltcholine and inhibition. In J. T. Tapp (Ed.), Reinforcement and behavior. New $x$ ork: Academic Press, 1969.

Douglas, R. J. The hippocampus and behavior. Psychological Bulletin, 1967, 67, 416-422.

Gormezano, I. Classical Conditioning. In J. B. Sidowski (Ed.) Experimental Methods and instrumentation in psychology.
New York: McGraw-Hill, 1966.

Lubow, R. E. Latent inhibition. Psychological Bulletin, 1973, $79,398-407$.

Lubow, R. E., Markman, R. E., \& Allen, J. Latent inhibition and classical conditioning of the rabbit pinna response. Journal of Comparative \& Physiological Psychology, 1968, 66, 688-694.

Lubow, R. E., \& Moore, A. U. Latent inhibition: The effect of non-reinforced preexposure to the conditioned stimulus. Journal of Comparative \& Physiological Psychology, 1959, 52 , 416-419.

Marchant, H. G., III, Mis, F. W., \& Moore, J. W. Conditioned inhibition of the rabbit's nictitating membrane response. Journal of Experimental Psychology, 1972, 95, 408-411.

Reiss, S., \& Wagner, A R CS habituation produces a "latent inhibition effect" but no active "conditioned inhibition." Learning \& Motivation, 1972, 3, 237-245.

Rescorla, R. A. Pavlovian conditioned inhibition. Psychological Bulletin, 1969, 72, 77-94.

Siegel, S. Retention of latent inhibition. Psychonomic Science $1970,20,161162$.

Siegel, S. Latent inhibition and eyelid conditioning. In $\mathrm{A} . \mathbf{H}$ Black and W. F. Prokasy (Eds)., Classical conditioning: Current theory and research. New York: Appleton-Century-Crofts, 1972.

Thompson, R. F., \& Spencer, W. A. Habituation: A model phenomenon for the study of neuronal substrates of behavior. Psychological Review, 1966, 73, 16-43.

\section{NOTE}

1. Figure 2 indicates that responding to light alone in the 95-d B groups was higher in summation testing than in the 75-d B groups $[t(30)=2.84, p<.01]$. This result is inexplicable since acquisition performance to light alone did not differ significantly for these two conditions $[t(30)<1]$.

(R eceived for publication August 1, 1974.) 